\title{
A extensão universitária como política pública nas desigualdades sociais e as contribuições do programa de educação tutorial na comunidade
}

\author{
University extension as a public policy on social inequalities and the contributions of the tutorial \\ education program in the community
}

La extensión universitaria como política pública sobre las desigualdades sociales y los aportes del programa de educación tutorial en la comunidad

Recebido: 20/07/2021 | Revisado: 24/07/2021 | Aceito: 26/07/2021 | Publicado: 01/08/2021

\author{
Byanca Viviane de Meneses Bicca \\ ORCID: https://orcid.org/0000-0002-5013-108X \\ Universidade Federal do Piauí, Brasil \\ E-mail: byanca1viviane@gmail.com \\ Luís Fernando Silva Marques \\ ORCID: https://orcid.org/0000-0002-7709-3538 \\ Universidade Federal do Piauí, Brasil \\ E-mail: luismarquesk5@gmail.com \\ Cecília Maria Resende Gonçalves de Carvalho \\ ORCID: https://orcid.org/0000-0002-8707-1447 \\ Universidade Federal do Piauí, Brasil \\ E-mail: ceciliamaria.pop@hotmail.com
}

\begin{abstract}
Resumo
No Brasil é possível a identificação massiva de cenários repletos de lacunas sociais e assolados pela desigualdade. Dessa maneira, as políticas públicas apresentam-se como instrumentos centrais para dirimir as disparidades no âmbito da sociedade. Tais iniciativas são desenvolvidas pelo Estado, através da égide do princípio do bem comum, e a partir da inter-relação com instituições sociais como as Universidades, centros de produção intelectual, há a otimização dos resultados dessas empreitadas sociais. O presente artigo tem como objetivo identificar os benefícios e os impactos da extensão universitária frente às desigualdades sociais. Para tanto, buscou-se apresentar, por intermédio de pesquisa bibliográfica, a estrutura do Programa de Educação Tutorial e a análise da sua contribuição como política pública a partir da atuação do grupo PET Integração da Universidade Federal do Piauí na comunidade. Conclui-se pela aplicabilidade eficaz das ações extensionistas na mitigação de discrepâncias sociais, figurando como ferramentas idôneas de política pública.
\end{abstract}

Palavras-chave: Ensino; Extensão universitária; Política pública; Desigualdade social.

\begin{abstract}
In Brazil, it is possible to massively identify scenarios full of social gaps and plagued by inequality. In this way, public policies are presented as central instruments to settle disparities within society. Such initiatives are developed by the State, through the principle of the common good, and from the interrelation with social institutions such as Universities, centers of intellectual production, there is the optimization of the results of these social endeavors. This article aims to identify the benefits and impacts of university extension in the face of social inequalities. To this end, we sought to present, through bibliographic research, the structure of the Tutorial Education Program and the analysis of its contribution as a public policy based on the performance of the PET Integração group at the Federal University of Piauí. It was concluded that the extension actions were effective in mitigating social discrepancies, figuring as suitable tools for public policy.
\end{abstract}

Keywords: Teaching; University extension project; Public policy; Social inequality.

\section{Resumen}

En Brasil, es posible identificar de forma masiva escenarios llenos de brechas sociales y plagados de desigualdad. De esta forma, las políticas públicas se presentan como instrumentos centrales para resolver las disparidades dentro de la sociedad. Tales iniciativas son desarrolladas por el Estado, bajo la égida del principio del bien común, y a partir de la interrelación con instituciones sociales como las Universidades, centros de producción intelectual, se optimiza los resultados de estos esfuerzos sociales. Este artículo tiene como objetivo identificar los beneficios e impactos de la extensión universitaria frente a las desigualdades sociales. Por lo tanto, se buscó presentar, a través de la investigación bibliográfica, la estructura del Programa de Educación Tutorial y el análisis de su contribución como política pública a partir de la actuación del grupo de Integración PET de la Universidad Federal de Piauí en la comunidad. Se concluye 
por la aplicabilidad efectiva de las acciones de extensión en la mitigación de las discrepancias sociales, apareciendo como herramientas acreditadas de política pública.

Palabras clave: Enseñanza; Extensión universitaria; Política pública; Desigualdad social.

\section{Introdução}

A sociedade brasileira, em sua conjectura histórica de formação, é marcada cotidianamente por realidades que apresentam um panorama de pobreza e desigualdades sociais que se transferem em todos os campos de dimensão da vida humana. Nesse sentido, cumpre salientar que o ordenamento jurídico do país prevê na Constituição Federal de 1988, em seu art. $3^{\circ}$, inciso III, o objetivo de: "erradicar a pobreza e a marginalização e reduzir as desigualdades sociais e regionais". Além disso, positiva, ainda, em seu art.6 $6^{\circ}$ a educação como um dos direitos sociais imprescindíveis para a construção de uma sociedade igual e justa para todas as idades (Brasil, 1988, s/p).

Percebe-se que, mesmo após a promulgação da Constituição Cidadã há mais de três décadas, o país ainda apresenta importantes situações de precariedade das condições de vida de segmentos sociais historicamente excluídos como uma questão não resolvida. O Índice de Desenvolvimento Humano (IDH) brasileiro ocupa o $84^{\circ}$ lugar entre 189 países, obtendo crescimento de 0,762 para 0,765 como mostra a síntese do mais recente Relatório do Desenvolvimento Humano 2020 (p.17), divulgado pelo Programa das Nações Unidas para o Desenvolvimento (Pnud, 2020). Apesar do crescimento do IDH, o Brasil caiu cinco posições no ranking quando comparado ao Relatório de 2019 (Pnud, 2019, p.303), demonstrando, assim, o lento ritmo de avanço em questões do trato da saúde, educação e renda que impactam diretamente nas disparidades dentro da sociedade.

Diante desse cenário, o Estado brasileiro apresenta-se conforme os deveres dados pelo ordenamento constitucional, sob a égide do princípio do bem-comum e tem como escopo central regular a sociedade, atender suas demandas e obstruir as lacunas sociais. Isso é feito, primordialmente, pela implantação e direcionamento de políticas públicas que Rodrigues define: "Políticas públicas são ações de Governo, portanto, são revestidas da autoridade soberana do poder público. Dispõem sobre 'o que fazer' (ações), 'aonde chegar' (metas ou objetivos relacionados ao estado de coisas que se pretende alterar) e 'como fazer' (estratégias de ação)" (Rodrigues, 2010, p. 53).

Nesse sentido, destaca-se o caráter genérico dessa conceituação, pois se "refere às ações governamentais que o estado desempenha em função do seu aspecto social, que vêm desde o welfare state Varguista e acabaram por desembocar na dicotomia social-liberal, tendo como agentes centrais o Estado e os cidadãos” (Marques et. al., 2021, p. 41.371).

Tamanho desígnio, entretanto, não é alcançado em sua integralidade por um esforço unilateral do Estado. É necessário, para tanto, a inter-relação institucional para atingir os objetivos almejados, já que as políticas públicas se propõem a alcançar todas as searas da sociedade. Nesse ínterim, as universidades, como centros de formação e de produção de conhecimento humano-científico e técnico, apresentam-se como entidades transformadoras da sociedade, conforme dispõe o Plano Nacional de Extensão Universitária (2001), elaborado pelo XVI Fórum de Pró-Reitores de Extensão das Universidades Públicas Brasileiras e pela Secretaria de Educação Superior do Ministério da Educação:

As universidades públicas brasileiras são instituições criadas para atender às necessidades do país. Estão distribuídas em todo o território nacional e em toda a sua existência sempre estiveram associadas ao desenvolvimento econômico, social, cultural e político da nação, constituindo-se em espaços privilegiados para a produção e acumulação do conhecimento e a formação de profissionais cidadãos. (Brasil, 2001, p.2)

Dessa forma, tem-se atrelado ao ambiente da academia, a função social inserida como basilar profícuo desde o processo de redemocratização do Brasil. Nessa conjuntura, há com a Carta Magna de 1988, um processo de introdução institucional da extensão universitária como atividade essencial do âmbito acadêmico, conforme preceitua o art. 207: "as universidades (...) obedecerão ao princípio de indissociabilidade entre ensino, pesquisa e extensão" - esta última, apesar de 
realizada no meio acadêmico anteriormente à carta constitucional vigente, possuía uma roupagem secundária, como é possível abstrair da Lei N. 5.540/68, já revogada, que definia a estrutura organizacional das universidades - compondo, assim, o tripé: Ensino, Pesquisa e Extensão. Tal tripé, em sua disposição tal qual é posta, colocando a extensão ao final, pode, inclusive, remeter a uma reflexão fática sobre uma relação de hierarquia e importância dada a cada faceta do trio dentro das academias. Historicamente, em face do ensino e da pesquisa, à extensão foi atribuído um papel secundário. Essa é uma realidade que deve ser modificada, ao passo que a visão academicista sobre o tripé deve ser horizontal e não vertical. Isso porque a extensão, igualmente ao ensino e à pesquisa, é primordial.

Tal primordialidade pode ser apreendida na sua conceituação - dentre tantas - feita pelo I Encontro de Pró-Reitores de Extensão das Universidades Públicas Brasileiras (Forproex, 1987):

A Extensão Universitária é o processo educativo, cultural e científico que articula o Ensino e a Pesquisa de forma indissociável e viabiliza a relação transformadora entre universidade e sociedade. A Extensão é uma via de mão dupla, com trânsito assegurado à comunidade académica, que encontrará, na sociedade, a oportunidade de elaboração da práxis de um conhecimento académico. No retorno à Universidade, docentes e discentes trarão um aprendizado que, submetido à reflexão teórica, será acrescido àquele conhecimento. Esse fluxo, que estabelece a troca de saberes sistematizados, académico e popular, terá como consequência: a produção do conhecimento resultante do confronto com a realidade brasileira e regional; a democratização do conhecimento académico e a participação efetiva da comunidade na atuação da Universidade. Além de instrumentalizadora desse processo dialético de teoria/prática, a Extensão é um trabalho interdisciplinar que favorece a visão integrada do social (Forproex,1987, p.11).

Diante disso, a discussão acerca da extensão como instrumento de política pública faz-se crucial no que se refere à eliminação das desigualdades nos diversos âmbitos da sociedade, uma tarefa complexa que exige a superação de enormes desafios. O presente trabalho, dessarte, propõe-se a compreender de que forma os programas extensionistas figuram como aparato interventivo de modificação e redução das disparidades sociais. Isso é feito, fundamentalmente, a partir da análise da atuação do Programa de Educação Tutorial (PET), modalidade interdisciplinar, criado a partir do Projeto "PET Integração: ação integrada em educação, cidadania e inclusão social”, da Universidade Federal do Piauí (UFPI). Desta forma, a institucionalização desse projeto veio estabelecer de maneira mais inclusiva a articulação ensino-extensão-pesquisa, representando um ineditismo e um novo caminho na implementação de ações que contribuam para garantir a ampliação do acesso e o sucesso da política de permanência dos estudantes na universidade.

Partindo do aqui exposto, o artigo debruça-se estruturalmente na definição, gênese, identificação dos objetivos do Programa de Educação Tutorial e em como pode contribuir na investida frente às desigualdades. A seguir, os esforços se concentram em apresentar a atuação do grupo PET Integração da UFPI e avaliar a concretude dos impactos de suas atividades extensionistas, enquanto políticas públicas, em disparidades sociais.

\section{Metodologia}

Trata-se de um estudo que utilizou à análise documental e a revisão de literatura para compreender de que forma os programas extensionistas figuram como aparato interventivo de modificação e redução das disparidades sociais. A pesquisa documental possibilita uma leitura aprofundada do assunto sem necessidade de contato do pesquisador com os sujeitos da pesquisa (Gil, 2002). Foi utilizada como fonte de dados da pesquisa documental o Manual de Orientações Básicas do PET (MOB), relatórios técnicos, leis, portarias e editais que instituíram o Programa.

A revisão bibliográfica, por sua vez, possibilita ao pesquisador identificar o que já foi produzido por diversos autores sobre sua temática de estudo, sendo imprescindível para não duplicar esforços e não chegar a lugares comuns (Marconi \& Lakatos 2003, p. 225). Ao ter o objetivo de "conhecer e analisar as principais contribuições teóricas existentes sobre um determinado tema ou problema" (Koche, 2011), preconizou a compreensão e a análise acerca do que foi produzido pelo grupo 
Pet Integração na prática extensionista e de que maneira suas ações impactam a comunidade, enquanto políticas públicas. Tal estudo se classifica, ainda, enquanto aspecto metodológico, como qualitativo ao preocupar-se no entendimento dos complexos fenômenos da realidade que não podem ser quantificados, centrando-se na compreensão e explicação da dinâmica das relações e da transformação social (Silveira \& Córdova, 2009).

\section{O programa de educação tutorial e os impactos de sua atuação}

\subsection{O surgimento e a natureza do Programa de Educação Tutorial (PET)}

Em 1979 a Coordenação de Aperfeiçoamento de Pessoa de Nível Superior (CAPES) criou o Programa Especial de Treinamento - PET desafiando as universidades a refletir sobre os seus objetivos e sua missão na formação qualificada dos graduandos. A partir de 2004, o Programa modificou a sigla e passou a ser identificado como Programa de Educação Tutorial, impulsionando um trabalho tutorial guiado pelos princípios do ensino, pesquisa e extensão, vinculado ao Ministério da Educação com financiamento do Fundo Nacional de Desenvolvimento da Educação (FNDE) e regulamentado pela Lei $\mathrm{N}^{\circ}$ 11.180/2005. Seu principal regimento, além da lei instituinte, dá-se por intermédio de portarias, instrumentos normativos infralegais, como as Portarias do Ministério da Educação Nº 976/2010 e No 343/2013, bem como pelo Manual de Orientações Básicas do PET, que tem como fim orientar acerca do funcionamento do programa concomitante a garantia da unidade nacional (Brasil, 2006).

O PET, em sua natureza convencional, surge com a formação de grupos organizados, formado por um tutor e 12 bolsistas, estudantes de graduação, a partir de um curso específico de graduação das instituições de ensino superior do país, como uma opção de melhoria da qualidade acadêmica, acompanhando o processo de modernização das universidades na compreensão da educação enquanto direito de todos (Brasil, 2013).

Hodiernamente, o PET é desenvolvido em 121 Instituições de Ensino Superior com 842 grupos (Kahhale et al; 2019). Na UFPI, o primeiro grupo foi iniciado no curso de História em 2006. Com o surgimento da modalidade PET interdisciplinar foi instituído o Projeto PET Integração: ações integradas em educação, cidadania e inclusão social, com a participação de estudantes dos cursos de Direito, Nutrição, Serviço Social, Pedagogia e Ciência da Computação, por meio do edital $\mathrm{n}^{\circ} 09$ PET/2010-MEC/SESU/SECAD.

No que tange aos seus objetivos, é notória a proposta de revolução educacional no ensino superior de forma a complementar a perspectiva convencional de educação nos cursos de graduação ao possibilitar uma gama de experiências aos discentes e tutores tanto no referente à produção acadêmica quanto na formação humana e cidadã através de reflexões, discussões, vivências e trabalho em equipe. Apesar de inúmeras dificuldades encontradas pelos grupos PET, como falta de financiamento, atraso de repasses, infraestrutura física precária, dentre outros, os estudos, as pesquisas e as ações extensionistas obtêm realizações imensuráveis em competência prática e ganhos de cunho acadêmico, pessoal e humanístico. Isso tudo a partir do engajamento conjunto de estudantes, tutores e demais agentes sociais em prol das atividades que realizam. (Carvalho, C.R, et al, 2018, p.42) Tal esforço é responsável pela efetivação da função social da universidade, sobretudo através da extensão.

Sobre a proposta do modelo pedagógico extensionista, o Manual de Orientações Básicas (2006) discorre:

A ação em grupo e a dedicação permitem desenvolver a capacidade de trabalho em equipe, facilitar a compreensão das características e dinâmicas individuais, bem como a percepção da responsabilidade coletiva e do compromisso social. A inserção do grupo dentro do curso permite que estas capacidades se disseminem para os alunos do curso em geral, modificando e ampliando a perspectiva educacional de toda a comunidade. Este desenvolvimento terá uma interação dinâmica com o projeto pedagógico do curso, em processo de mútuo aperfeiçoamento (Brasil, 2006, p.6). 
Deduz-se a partir da definição dos objetivos pelos instrumentos regulatórios, a primazia do valor social de aproximação entre a sociedade e a universidade. Dentre os objetivos cabe destaque, para melhor visualização, o art $2^{\circ}$ da Portaria No 976 do Ministério da Educação, de 10 de julho de 2010:

Art. $2^{\circ}$ O PET (...) que tem por objetivos: I - desenvolver atividades acadêmicas em padrões de qualidade de excelência, mediante grupos de aprendizagem tutorial de natureza coletiva e interdisciplinar; $\mathbf{V}$ - estimular o espírito crítico, bem como a atuação profissional pautada pela cidadania e pela função social da educação superior; VIII - contribuir com a política de diversidade na instituição de ensino superior - IES, por meio de ações afirmativas em defesa da equidade socioeconômica, étnico-racial e de gênero (Brasil, 2010, s/p).

É inegável que o programa tutorial busca a otimização da educação superior com proposta interdisciplinar e multifacetada. A integração de cursos superiores de diversas áreas entre si e entre a sociedade, que agrega realidades dinâmicas e complexas, é, sem dúvida, uma grande oportunidade de conhecimento humano que transcende a academia. Ofertar ao discente a experiência de conviver e atuar, aplicando seus conhecimentos e habilidades, em realidades diferentes da sua, traz, indiscutivelmente, enriquecimento e certa modificação na forma de pensar o modelo educacional e a própria produção academicista. A partir dessa relação entre o ensino, a pesquisa e a extensão no ensino superior, obtém-se o aprofundamento dos conhecimentos referentes aos pilares da educação dentro das próprias instituições de ensino. (Castilho, et al., 2019, p.241) Contudo, o que o Programa de Educação Tutorial pode proporcionar além dos benefícios aos seus atores, além dos muros da universidade?

O Relatório de Desenvolvimento Humano (2019), ao fazer a análise das desigualdades, considera a questão das capacidades cruciais para a discussão. Tais capacidades se definiriam, fundamentalmente, em básicas e avançadas de forma que, cada vez mais, faz-se essencial que se busque a diminuição do distanciamento entre as pessoas e as capacidades avançadas. Isso porque estas últimas, segundo o relatório, estão no âmago do desenvolvimento humano e proporcionariam a liberdade às pessoas sobre suas próprias vidas. Seria, por exemplo, ensinar uma pessoa a escrever o seu nome (capacidade básica), mas não proporcioná-la a oportunidade de ser escritor ou estudar Letras (capacidade avançada). Assim, uma limitação incapacitante e provavelmente intransponível - já que nas mesmas condições as deficiências tendem aumentar ao longo da vida - restringe a liberdade de escolha do indivíduo sobre suas oportunidades.

A partir dessa perspectiva, é possível iniciar a compreensão acerca dos impactos do programa extensionista. "Para além dos muros da academia" poderia figurar, inclusive, como slogan do projeto. A extensão universitária atua como instrumento que leva a universidade para além da comunidade acadêmica. Ela transpõe os muros das instituições e as colocam dentro da sociedade como um todo de forma a ampliar as oportunidades e, consequentemente a liberdade, de pessoas em condição de desigualdade. A quebra desse distanciamento tem como consequência, dentre tantas, a democratização do conhecimento, a potencialização da função social das instituições superiores, e a acessibilidade às "capacidades avançadas".

\subsection{O programa de educação tutorial na Universidade Federal do Piauí}

Com suas inúmeras possibilidades de contribuições advindas do esforço coletivo e da potência formada por diversos olhares, sinalizando outras formas de organização que empreendeu-se para superar as formas tradicionais do ensino universitário instituído na academia, a partir de 2010, o PET adquiriu novos contornos por incluir em sua matriz estudantes de cursos diversos. Os objetivos do programa foram ampliados para além de desenvolver atividades em padrões de excelência, e passam a ter natureza interdisciplinar, articulando a competência acadêmica para o compromisso social da universidade e direcionados para minimizar as desigualdades sociais. Assim, na UFPI o PET passa a ter uma vinculação direta com a PróReitoria de Extensão e Cultura (PREXC); seguindo a regulamentação da Portaria nº 313/2013 do Ministério da Educação. 
Nesse sentido, o PET passou a constitui-se em uma possibilidade concreta de construção de uma nova relação entre os estudantes e a academia. Alguns dos grupos PET/UFPI apresentam atuação nas mais diversas áreas do conhecimento: ciências da saúde, humanas, sociais, engenharias e tecnologia. No âmbito dos projetos, essas ciências podem se integrar e se interrelacionar como metodologia de ampliação da eficiência e da eficácia das ações extensionistas no alcance social e na produção de conhecimento. Tem-se, como um dos principais projetos nesse formato, o PET Integração que é formado pelos cursos de Nutrição, Direito, Serviço Social, Pedagogia e Ciência da Computação - sem prejuízo à interdisciplinaridade com outros cursos.

Nesse prisma, o grupo PET Integração desenvolve esforços sobre o tripé Ensino, Pesquisa e Extensão com o fito de contribuir, significativamente, com a produção científico-acadêmica, com o aperfeiçoamento no ensino dos cursos de graduação em geral - não somente na formação individual dos discentes extensionistas - e atuar como instrumento interventivo nas lacunas sociais.

\subsection{O PET e o tripé ensino, pesquisa e extensão}

Notórias são as ações de Ensino, Pesquisa e Extensão do grupo PET Integração. Nesse processo, o diálogo é conduzido para o aprimoramento da qualificação dos estudantes sempre articulando as dimensões ensino, pesquisa e extensão, considerando que grande parte dos acadêmicos chegam sem experiências nesses campos fundamentais de atuação. Para essas atividades é construído um projeto de formação multidisciplinar para os petianos vinculados à cursos de pós-graduação na perspectiva de sua atuação como protagonista na universidade e nos territórios sociais.

Com efeito, como produção acadêmica do grupo destaca-se a publicação dos livros: "Interdisciplinaridade e Experiências Educacionais e Sociais no Programa de Educação Tutorial” lançado no Salão de Livros do Piauí (SALIPI) em 2019 e "Construindo Elos: Pet Integração e Pet Saúde" com lançamento no SALIPI em 2016, com autoria dos alunos dos grupos PET, sob orientação dos professores e tutores do programa.

Muitas outras obras já foram produzidas no âmbito do PET, bem como a publicação dos resultados das pesquisas em revistas indexadas e dos inúmeros trabalhos apresentados em eventos acadêmicos como o Simpósio Internacional de Estado, Sociedade e Políticas Públicas (SINESPP); Encontro Regional dos Grupos PET (ENEPET); Encontro Nacional dos grupos PET (ENAPET); Encontro local dos grupos PET (INTERPET); congressos, entre muitos outros eventos científicos local, regional e nacional (Carvalho et al., 2018; Silva et al., 2019, s/p).

A excelência do grupo é reconhecida, inclusive, por premiações. Em 2018, o PET Integração conquistou o $1^{\circ}$ lugar na área de educação no VIII Seminário de Extensão e Cultura (SEMEX), ratificando o compromisso e o potencial do programa. Além disso, o fomento ao ensino extensionista promovido pelo grupo tem uma contribuição determinante na democratização do conhecimento e na política de inclusão social. Para a análise desta assertiva cabe o destaque de alguns projetos.

Em 2019, foi posto em prática o projeto "Educação Jurídica", desenvolvido pelos integrantes do Pet Integração no Centro de Ensino de Tempo Integral Professor Darcy Araújo. Esse projeto consistiu em aulas planejadas, em adequação à realidade encontrada e ao público-alvo, sobre conhecimentos jurídicos básicos da Constituição Federal e direitos fundamentais, incluindo o direito à alimentação saudável. A difusão do conhecimento básico do Direito feito pelo projeto, possibilitou aos jovens o conhecimento acerca de seus direitos e deveres de modo a contribuir na formação cidadã dentro da escola.

No ano de 2020, mesmo com o cenário de exceção da pandemia da covid-19, o grupo PET conseguiu dar continuidade ao projeto. A partir da reestruturação do planejamento e adaptação das atividades, a extensão alcançou escolas com aulas remotas sobre Direito, Saúde, oficina de redação e discussão de temas pertinentes ao Exame Nacional do Ensino Médio (ENEM). A resistência e dinamicidade do PET mostra-se importante, pois, diante do Estado Democrático de Direito em que se consagra o Brasil - art. ${ }^{\circ} \mathrm{CF}$ - é imprescindível - e preconizado pelo ordenamento - o exercício da cidadania, a 
reflexão ativa e crítica dos cidadãos e a participação social. No entanto, tal formação só será obtida pela educação, como destaca Marlene Ribeiro (2002): “[...] pensadores modernos identificam a educação como um caminho para a conquista de direitos sociais. Assim, no que tange à cidadania, parece haver um consenso de que sua conquista implica o conhecimento de direitos e deveres por meio de uma sólida educação escolar básica" (Ribeiro, 2002, p. 23).

É transparente, dessa forma, que a educação prescinde à cidadania plena e, sobretudo, a educação jurídica. Isso porque o conhecimento amplamente difundido de noções básicas do ordenamento jurídico proporcionaria as pessoas, desde jovens, em idade escolar básica, a conhecer seus direitos e deveres perante o Estado e à sociedade. Assim, poderiam exercer, de forma mais ativa e consciente, sua cidadania. Contudo, esse formato de ensino não é encontrado atualmente, de forma ampla, nas grades curriculares das escolas, principalmente públicas, o que gera deficiências na formação cidadã provenientes da lacuna educacional e, consequentemente, vulnerabilidades sociais.

Nesse contexto, identifica-se a importância de ações como o "Educação Jurídica e Nutricional" desenvolvidas singularmente, considerando as limitações conjunturais de cada realidade ao mesmo tempo que objetiva contribuir com a modificação do cenário estrutural de fragilização e desigualdade.

Ademais, o programa de extensão ainda promove a criticidade, acolhimento dentro e fora da própria universidade, aprimoramento do conhecimento dos discentes com a promoção de cursos como o "Escrita cientifica", aberta a toda comunidade, o minicurso pré-período voltado aos ingressantes da graduação em Direito da UFPI sobre os aspectos da graduação e informações norteadores sobre a pesquisa, o método científico e o VI Bate Papo Acadêmico, organizado conjuntamente entre os PET's Integração, Pedagogia, Serviço Social e Potência acerca do tema "A crise do capital e seus impactos na educação" que contou com debates, palestras e apresentação cultural. Todos os mencionados projetos foram realizados em 2019.

Outro projeto que merece destaque, é o Projeto Bela Velhice (2018) e Informática para Idosos (2014 e 2018). Eles foram desenvolvidos pelo grupo de extensão PET Integração juntamente ao Programa Terceira Idade em Ação (PTIA) programa de extensão desenvolvido pela Universidade Federal do Piauí por cerca de 20 anos voltado a pessoas com mais de 50 anos, em Teresina e cidades do interior, com atividades como música, dança, línguas e cursos - e têm em comum o foco nas demandas do público idoso. Esses projetos tiveram como objetivo entender o envelhecimento, promover a troca de saberes intergeracionais, a inclusão digital e o cuidado com a saúde mental, nutricional e física dos idosos por intermédio de debates sobre temas como "humor", "autoestima" e "alimentação" e de oficinas sobre noções básicas de informática, internet e redes sociais.

Tais ações mostram-se como aparatos de defesa a um direito personalíssimo: o envelhecimento. Sobre isso, dispõe a Lei $n^{\circ} 10.741$ em seu Art. 8ํ: "o envelhecimento é um direito personalíssimo e a sua proteção um direito social”. É defeso ainda ao idoso no art $2^{\circ}$ “(...) todas as oportunidades e facilidades, para preservação de sua saúde física e mental e seu aperfeiçoamento moral, intelectual, espiritual e social, em condições de liberdade e dignidade" (Brasil, 2003). Apreende-se, dessa forma, pela própria letra da lei, os benefícios gerados pelas ações extensionistas.

Outro instrumento importante foi a Estratégia Global da Organização Mundial da Saúde (OMS) sobre Alimentação Saudável, Atividade Física e Saúde aprovado na 57 assembleia Mundial da Saúde, em 2004. Com efeito, esse documento coloca a questão da alimentação e da atividade física em lugar de destaque na promoção da saúde, prevenção de doenças e agravos de comorbidades (OMS, 2004).

Percebe-se que há uma riqueza de leis e instrumentos que buscam garantir ao idoso, por questões legais e humanitárias, o acolhimento, o cuidado e a integração no âmbito da sociedade, percebendo-o como agente capaz e sujeito de direitos. No sentido de assegurar que o envelhecimento corra de forma digna e saudável, as políticas públicas devem ser pensadas e sensíveis as situações de vulnerabilidade em que os idosos estão inseridos. 
Assim, a eficácia desses projetos de extensão como políticas públicas dá-se, principalmente, pela sensibilidade dos atores ao cenário encontrado e atuação singular pormenorizada. Os grupos, antes de darem início as ações, se integram ao público-alvo e propõem-se a compreender as demandas internamente a fim de desenvolver de forma eficaz, acessível e humana as atividades. Dessa forma, os projetos extensionistas garantiram os direitos desses idosos, evitando que eles fossem inseridos em um novo panorama de desigualdade, sobretudo, atuando para dirimir as lacunas existentes.

\subsection{O PET como uma política pública dinâmica}

Em 2020, o mundo enfrentou uma crise sem precedentes provocada pelo vírus denominado Covid-19 - uma nova variação de coronavírus. No Brasil, o agravamento deu-se em meados do mês de março e toda a sociedade foi mobilizada em prol do combate à pandemia. Medidas como isolamento social e lockdown foram decretadas e a dinâmica da vida social modificou-se drasticamente concomitante ao surgimento de novas demandas sociais.

Diante dessa nova realidade, surgiu a necessidade, em todas as áreas, de redefinição para atender as novas demandas com rapidez. No âmbito da educação, mesmo com escolas e universidades paradas, os projetos extensionistas continuaram suas atividades e buscaram adequar-se à nova conjuntura com o escopo de contribuir com a sociedade.

A função social da extensão universitária do Programa de Educação Tutorial, na modalidade Integração, da Universidade Federal do Piauí, desenvolveu-se a partir da dinamicidade na criação de ações imprescindíveis ao momento. Em prosseguimento, as atividades do grupo foram efetuadas, em sua maioria, remotamente com o uso da tecnologia e das redes sociais como o Instagram, plataforma google meet, esforçaram-se na seara informacional e de educação comportamental.

Dentre as atividades desenvolvidas, cabe mencionar a cartilha "Conheça e Previna-se contra a Covid-19" que contém informações sobre a higienização pessoal, de alimentos e de objetos, sobre a prevenção, alimentação e hábitos saudáveis, dicas para ajudar a passar pelo período de isolamento social, além dos cuidados com grupos de risco como os idosos; o projeto de extensão PET Informa; publicações nas páginas do PET Integração, de cunho informacional, com textos e imagens sobre problemáticas agravadas com o isolamento social como a violência contra a mulher e orientações pormenorizadas e didáticas acerca de políticas governamentais de assistência social como o auxílio emergencial.

Durante esse período de distanciamento social e inclusive de suspensão das atividades presenciais do PET Integração, o Projeto PET Informa, que objetivava a publicação semanal de temáticas implementadas ordinariamente pelas atividades do Programa, nas redes sociais. Nesse sentido, o projeto ainda capitaneou trabalhos que foram desenvolvidos, revisados e aprimorados e, sequencialmente, condensados em uma obra coletiva intitulada "Diálogos em Tempos de Pandemia", livro digital publicado no segundo semestre de 2020, que se fundamenta no compartilhamento de estudos, pesquisa e ações de extensão distribuídos em seus 14 capítulos.

Nota-se, portanto, que a extensão é capaz de contribuir com a sociedade, mesmo em tempos incertos, de forma dinâmica, significativa e basilar. A participação do grupo de extensionistas pelo PET articulando conjuntamente atividades de ensino-pesquisa-extensão contribui para a formação global do estudante e para o fortalecimento do compromisso social da universidade.

\section{Considerações Finais}

As prerrogativas constitucionais reconhecem as disparidades sociais existentes no âmbito da sociedade brasileira e dispõe como objetivo e dever do Estado a promoção da sociedade igual e o combate à desigualdade. Diante dessas atribuições, o Estado possui, como principais meios interventivos às demandas sociais, as políticas públicas. A implementação destas ferramentas é proposta nas mais variadas searas da sociedade e necessita, para maior amplitude de eficácia, se inter-relacionar 
com os direitos sociais - já que estes mostram-se, a partir de sua regulamentação no ordenamento constitucional de 1988, como imprescindíveis na transformação de realidades díspares.

Dentre tais direitos sociais, destaca-se a educação. Tal direito, tido como um dos principais agentes de formação e desenvolvimento humano, faz a aplicabilidade de políticas públicas, por intermédio da educação, primordial. Dessa forma, as universidades como centros de produção do conhecimento científico e formação humana e, tendo a função social introduzida em seu âmago desde a redemocratização como característica precípua, apresentam-se como importantes instituições de desenvolvimento e atuação no que se refere às políticas públicas.

Nesse âmbito, a extensão universitária mostra-se promissora, com vasta e rica produção e fomento no tripé Ensino, Pesquisa e Extensão. O Programa de Educação Tutorial, PET Integração da Universidade Federal do Piauí, como programa de extensão efetiva, por meio de suas ações extensionistas, a excelência almejada nas disposições legais. Infere-se tal assertiva a partir do destaque e análise e projetos do grupo em que se pode observar impactos como a acessibilidade das ações, a aproximação entre a universidade e as diversas realidades sociais, a vasta produção acadêmica, o fomento ao ensino e à formação cidadã no ensino superior, a democratização do conhecimento e a capacidade dinâmica de alcance social e de se reinventar frente às adversidades e à complexa mutação social.

Entende-se, portanto, a extensão como detentora de prerrogativas que a fazem eficaz e idônea como política pública de mitigação das desigualdades sociais, devendo, assim, ser incentivada e valorizada, principalmente em momentos de exceção. Percebeu-se a capacidade de reinvenção da extensão universitária em meio a todas as dificuldades impostas ao grupo PET Integração pelas diversas realidades. Isso mostra a resistência e dinamicidade da extensão que deve ser mais explorada, incentivada, financiada e estudada para compreender sua atuação, suas limitações, seus impactos e, assim, otimizar suas ações, aumentando sua eficácia e alcance, para que as ações extensionistas figurem, cada vez mais, como políticas públicas transformadoras dentro de cenários permeados pela desigualdade.

De tudo isso, considera-se imensurável a dimensão do trabalho extensionista na formação política, acadêmica e científica dos estudantes e na atuação do compromisso da universidade, sobretudo frente aos grupos excluídos socialmente, podendo-se destacar a ampliação e o fortalecimento da luta pela democratização do ensino público; o aperfeiçoamento acadêmico, político e humanístico; a qualificação para a produção científica; a identificação de talentos; a aproximação entre diferentes saberes acadêmicos e entre o conhecimento científico e popular, favorecendo a interdisciplinaridade e o exercício de cidadania.

\section{Agradecimentos}

Ao Fundo Nacional de Desenvolvimento da Educação - FNDE/MEC, pela concessão de custeio e bolsas aos petianos do Grupo PET Integração/UFPI.

\section{Referências}

Brasil. (1968). Lei $n^{\circ} 5.540$, de 28 de novembro de 1968. Fixa normas de organização e funcionamento do ensino superior e sua articulação com a escola média, e dá outras providências. Diário Oficial da República Federativa do Brasil, Brasília, DF http://www.planalto.gov.br/ccivil_03/leis/L5540.htm.

Brasil. (1988). Constituição da República Federativa do Brasil de 1988 . Senado Federal: Centro Gráfico, 1988. http://www.planalto.gov.br/ccivil_03/constituicao/constituicao.htm.

Brasil. (2003). Lei n 10.741 , de 1 de outubro de 2003. Dispõe sobre o Estatuto do Idoso e dá outras providências. Diário Oficial da República Federativa do Brasil, Brasília, DF. http://www.planalto.gov.br/ccivil_03/leis/2003/110.741.htm.

Brasil. (2005). Lei No 11.180, de 23 de setembro de 2005. Institui o Programa de Educação Tutorial - PET. Diário Oficial da República Federativa do Brasil, Brasília, DF. http://www.planalto.gov.br/ccivil_03/_ato2004-2006/2005/lei/111180.htm.

Brasil. (2006). Ministério da Educação. Manual de Orientações - PET. http://portal.mec.gov.br/pet/manual-de-orientacoes. 
Brasil. (2010). Ministério da Educação. Portaria n ${ }^{\circ}$ 976, de 27 de julho de 2010. Diário Oficial da República Federativa do Brasil, Brasília, DF. http://portal.mec.gov.br/index.php?option=com_docman\&view=download\&alias=6647-portaria-mec-976-27-07-2010\&category_slug=setembro-2010pdf\&Itemid=30192.

Brasil. (2013). Ministério da Educação. Portaria nº 343, de 24 de abril de 2013. Diário Oficial da República Federativa do Brasil, Brasília, DF. https://www.ufpi.br/pet.

Brasil. (2018) Ministério da Educação. Apresentação PET. http://portal.mec.gov.br/pet.

Carvalho, C. R., Barros, R. O., Reis, E. P., Araujo, L. B., \& Sousa, H. M. H. (2018). O Programa de Educação Tutorial (PET) no contexto da crise econômica brasileira. Revista Extensão em Foco, p. 28 - 45. https://revistas.ufpr.br/extensao/article/view/52730.

Castilho, W. S., Castilho, D. D., \& Dias, R. C. (2019). A pesquisa, o ensino e a extensão no estágio supervisionado dos cursos de licenciatura em física: reflexões sobre uma proposta. Revista Eletrônica Científica Ensino Interdisciplinar, 5(14), p.237-249. http://periodicos.uern.br/index.php/RECEI/article/view/3267/2037.

Diniz, F. P. (2012). A Extensão Universitária como Instrumento de Política Pública. (Dissertação de Mestrado em Ciências Humanas, Universidade Federal de Goiás, Goiânia). http://repositorio.bc.ufg.br/tede/handle/tde/1614.

Franco, F. G. (2019). O acesso à educação jurídica como meio de contribuir para a formação da sociedade. Conteúdo Jurídico. https://conteudojuridico.com.br/consulta/artigos/53034/o-acesso-a-educacao-juridica-como-meio-de-contribuir-para-a-formacao-da-cidadania.

I Encontro de pró-reitores de extensão das universidades públicas brasileiras. (1987). Conceito de extensão, institucionalização e financiamento. https://www.ufmg.br/proex/renex/images/documentos/1987-I-Encontro-Nacional-do-FORPROEX.pdf.

Gil, A. C. (2002). Como elaborar projetos de pesquisa. São Paulo: Atlas.

Kahhale, E. M. S. P., Gattai, M. C. P., Kato, R. A. F., Paparelli, R., \& Tosta, R. M. (2019). Rumo aos 25 anos de história do Programa de Educação Tutorial (PET/MEC/SESu) na PUC-SP. Psicologia. Revista., 28(n. especial), p.593-623.

Köche, J C. (2011). Fundamentos de metodologia científica. $\quad$ Editora $\quad$ Vozes. p. $122-126$. http://www.adm.ufrpe.br/sites/ww4.deinfo.ufrpe.br/files/Fundamentos_de_Metodologia_Cienti\%CC\%81fica.pdf.

Lakatos, E. M., \& Marconi, M. A. (2003). Fundamentos de metodologia científica. (5 ${ }^{\mathrm{a}}$ ed.) Editora Atlas. p.220- 235. http://docente.ifrn.edu.br/olivianeta/disciplinas/copy_of_historia-i/historia-ii/china-e-india/view.

Marques, L. F. S., Silva, F. J. B., \& Brito, R. M. M. (2021). A participação popular como instrumento de fiscalização e controle social dos gastos públicos. Brazilian Journal of Development, 7(4), p. 41.368-41.383. https://www.brazilianjournals.com/index.php/BRJD/article/view/28691/22667.

Organización mundial de la salud. (2004). Estrategia mundial sobre régimen alimentario, actividad física y salud. Ginebra: OMS.

Programa de desenvolvimento das nações unidas. (2019). Relatório de Desenvolvimento Humano. http://hdr.undp.org/en/2019-report.

Programa de desenvolvimento das nações unidas. (2020). Síntese do Relatório de Desenvolvimento Humano. http://hdr.undp.org/sites/default/files/hdr_2020_overview_portuguese.pdf.

Ribeiro, M. (2002). Educação para a cidadania: questão colocada pelos movimentos sociais. Revista Educação e Pesquisa, 28(2), p.113-128 https://www.researchgate.net/publication/26374733_Educacao_para_a_cidadania_questao_colocada_pelos_movimentos_sociais.

Rodrigues, M. M. A. (2010). Políticas Públicas. São Paulo: Publifolha.

Silva, A. G. F., Mota, L. A., Dornelas, C. S. M., \& Lacerda, A. V. (2017). A relação entre Estado e políticas públicas: uma análise teórica sobre o caso brasileiro. Revista Debates, 11(1), p 25-42. https://seer.ufrgs.br/debates/article/view/72132.

Silva, D. (2019). Relato de experiências do grupo PET Integração: ação integrada em educação, cidadania e inclusão social da Universidade Federal do Piauí (Teresina, Piauí). In: BRITO, D.A (org.). PET: 40 anos de Ensino, Pesquisa e Extensão, Porto Alegre: PLUS/Simplíssimo.

Silveira, D. T., \& Córdova, F. P. (2009). A pesquisa científica. In: Gerhardt, T. E., \& Silveira, D. T. [Org.]. Métodos de pesquisa: Editora da UFRGS. 33-44. http://www.ufrgs.br/cursopgdr/downloadsSerie/derad005.pdf.

XVI Encontro de pró-reitores de extensão das universidades públicas brasileiras. (2001). Plano Nacional de Extensão Universitária. https://files.cercomp.ufg.br/weby/up/694/o/PNEX.pdf. 